\title{
The Selective Separation and Stabilization of Arsenic from Primary and Secondary Sources
}

\author{
Dr. Corby G. Anderson \\ Harrison Western Professor \\ Mining Engineering \& George S. Ansell Department of Metallurgical and Materials Engineering \\ Colorado School of Mines, USA \\ Dr. Larry G. Twidwell \\ Department of Metallurgical and Materials Engineering \\ Montana Technological University, USA
}

Globally, the regulation of arsenic emissions has increased while the tangible uses of arsenic have decreased.

These trends continue. Therefore, the separation of arsenic from primary and secondary sources and its stabilization and effective management is imperative. This presentation will provide a background on pertinent aspects of arsenic. Based upon the author's experience, examples of both pyormetallurgical and hydrometallurgical separations will be illustrated. Finally, a discussion of effective arsenic fixation and stabilization technology will be provided. 